\title{
The Standard Interpretation of Schopenhauer's Compensation Argument for Pessimism: A Nonstandard Variant
}

\begin{abstract}
According to Schopenhauer's compensation argument for pessimism, the nonexistence of the world is preferable to its existence because no goods can ever compensate for the mere existence of evil. Standard interpretations take this argument to be based on Schopenhauer's thesis that all goods are merely the negation of evils, from which they assume it follows that the apparent goods in life are in fact empty and without value. This article develops a non-standard variant of the standard interpretation, which accepts the relevance of the negativity thesis but rejects that the argument assumes that life's goods are all empty and valueless. Instead, it argues that whatever value negative goods might possess, they do not have the kind of value to compensate for positive evils. This involves additional development of the negativity thesis and a defence of it against Simmons's (2021) objections.
\end{abstract}

\section{Introduction}

Schopenhauer claims that suffering is essential to all life, that life is not worth living, and that the world should not exist. In chapter 46 of the second volume of The World as Will and Representation $(W W R$ ), titled 'On the Nothingness and Suffering of Life', he presents a series of short arguments in defence of these pessimistic claims. These arguments supplement those presented in $\$ \S 56-59$ of the first volume of the same work, where it is demonstrated that pain and suffering are universal and inescapable in life. One such argument has attracted attention from several commentators:

it is fundamentally beside the point to argue whether there is more good or evil in the world: for the very existence of evil already decides the matter since it can never be cancelled out by any good that might exist alongside or after it, and cannot therefore be counterbalanced ... For even if thousands had lived in happiness and delight, this would never annul the anxiety and tortured death of a single person; and my present well-being does just as little to undo my earlier suffering. If therefore the evil were a hundred times less in the world than is the case, then the mere existence of evil would still be sufficient to ground [the] truth ... that we should be sorry rather than glad about the existence of the world ... (SW 3: 661/WWR 2: 591-2)

According to this argument, a life is preferable to non-existence only if its goods compensate for its evils, but since the only goods we receive in life cannot compensate for the evils we must endure, our lives are not worth living. In the above formulation, Schopenhauer goes so far as to insist that the mere existence of evil already decides the matter, so that if a life were to contain a single evil, it would thereby not be worth living. 
Until recently, commentators have usually addressed Schopenhauer's compensation argument in passing, as part of wider discussions of his pessimism or still wider discussions of the balance between good and evil. ${ }^{1}$ They have puzzled over why, according to Schopenhauer, goods can never compensate for evils. Byron Simmons (2021) has recently been the first to undertake a dedicated discussion of how the argument works.

Simmons reads the compensation argument as claiming that the temporal arrangement of life's goods and evils make it impossible for goods to compensate for evils. This reading attributes to Schopenhauer the assumptions that interpersonal compensation is impossible (goods had by one person can never compensate for evils had by another person) and crosstemporal, intrapersonal compensation is also impossible (goods had by a person at one time can never compensate for evils had by the same person at another time). So long as no good is had by a person at the same time as some evil, no good ever compensates for any evil. This reading takes its cue from the temporal language used by Schopenhauer in the passage quoted above as well as passages nearby.

Simmons criticises a reading of the compensation argument which he calls the standard interpretation. This paper reconsiders the standard interpretation in the light of Simmons's objections. It defends what Simmons calls a 'nonstandard variant' of the standard interpretation (2021: 133 n.7). A standard interpretation of the compensation argument 'takes its cue from ... the negativity thesis' and, standardly, it 'assumes that compensation for life's evils is supposed to be impossible because the goods in life are all empty and without value' (Simmons 2021: 122 3). The non-standard variant defended in this paper does take its cue from the negativity thesis, but it does not assume that compensation for life's evils is supposed to be impossible because the goods in life are all empty and without value.

Instead, it develops the negativity thesis as a basis for the compensation argument in three main ways (Section 2). First, it argues that while Schopenhauer states that pleasures cannot be 'felt positively', he does not think that they cannot be felt at all (2.1). Second, it argues that, according to Schopenhauer, pleasure can be stimulated by reflection on possible states of suffering that have been relieved or prevented (2.2.). Third, it argues that while goods that can only be felt indirectly might have some kind of value, they do not have the kind of value that could repay any positive evils that are felt directly (2.3).

The remainder of the paper uses Simmons's objections to the standard interpretation of the compensation argument to develop the details of this non-standard variant (Sections 3 and 4). Crucially, the non-standard variant does not attribute to Schopenhauer (as most standard interpretations tacitly do) the assumption that something can have value for us only if we can directly experience it. At the same time, it maintains (as most standard interpretations tacitly do not) that the compensation argument is not undermined by allowing that negative goods and indirect pleasures can have some kind of value for us.

\section{Developing Schopenhauer's Negativity Thesis}

\subsection{Indirect Pleasures}


In $\S 58$ of the first volume of $W W R$, Schopenhauer presents the view that happiness is no more than the negation of suffering (SW 2: 376-78/WWR 1:345-47). His presentation of the negativity of happiness follows a detailed demonstration of 'how essential suffering is to all life' (SW 2: 366/WWR 1: 337). The negativity thesis pre-empts any attempt to mitigate the pervasiveness of suffering by appeal to the facts of happiness. According to Schopenhauer, we are generally mistaken about what happiness is and can be. He says: 'what is generally called happiness is actually and essentially only ever negative and absolutely never positive' (SW 2: 376/WWR 1: 345). Happiness is always negative because 'a desire, i.e. a lack, is the prior condition for every pleasure,' but 'the desire ends with satisfaction and so, consequently, does the pleasure' (SW 2: 376/WWR 1: 345). What is generally called happiness is no more than relief from the pain of desiring itself.

In the second volume of $W W R$, Schopenhauer reaffirms the negativity thesis just before he presents the compensation argument. He extends the negativity thesis to goods other than happiness and highlights its psychological aspect:

We feel pain, but not painlessness; we feel worry, but not freedom from worry; we feel fear but not security. We feel a desire as we feel hunger and thirst; but as soon as it is fulfilled, it is like a bite of food we have enjoyed, which stops existing for our feeling the moment it is swallowed. We feel the painful loss of pleasures and joys as soon as they are gone: but pains even if they are present for a long time before departing, are not immediately missed; if we think of them at all it is intentionally by means of reflection. For only pain and lack can be felt positively and therefore register their presence: well-being on the other hand is merely negative. (SW 3: 659-60/WWR 2: 590)

As Simmons (2021: 123) notes, to say that only pain and lack can be felt positively is not to say that pleasure cannot be felt at all. Rather, the transition from pain to painlessness can be a pleasant experience. Schopenhauer even implies the possibility of intensely pleasant feelings: as essentially intense relief, their intensity is proportionate to that of the pain from which they are the relief: 'Great, vivid joys can only be conceived as the result of a great preceding misery' (SW 3: 660/WWR 2: 590). Following the Epicureans, these pleasures can be classified as 'kinetic': they are the joys and delights that may accompany the transition from pain to painlessness achieved in the fulfilment of a need or desire (for example, drinking when thirsty), as distinct from the 'static' pleasure found in a persisting state of freedom from disturbance or suffering (for example, having a quenched thirst). ${ }^{2}$

Rather than denying the existence of pleasant feelings, then, Schopenhauer's point is to highlight asymmetries in how pleasant and painful feelings occur. Only painful feelings, as the presentation of positive bad, are ever 'given to us directly [unmittelbar gegeben]' or 'announce themselves directly [unmittelbar Ankündigende]' (SW 2: 377/WWR 1: 346), and therefore 'register their presence [kündigen daher sich selbst an]' (SW 3:660/WWR 2: 590). 
Pleasant feelings, by contrast, as the presentation of negative good, are recognised 'only indirectly [nur mittelbar erkennen]' (SW 2: 377/WWR 1: 346), since 'pains ... are not immediately missed [nicht unmittelbar vermi $\beta t]$ ' and 'if we think of them at all it is intentionally, by means of reflection [mittelst der Reflexion]' (SW 3: 659/WWR 2: 590). We can feel good, then, but we can also fail to feel good, and we often do; whereas we rarely miss an opportunity to feel bad.

\subsection{Stimulating Indirect Pleasure}

As some of these remarks already indicate, Schopenhauer suggests that these indirectly felt pleasures can be stimulated by reflection on pain that has been relieved or prevented:

we enjoy remembering needs, illnesses, wants and similar things that we have survived, because this is the only way for us to enjoy our present possessions. Nor can it be denied that in this respect ... the sight or description of other people's suffering gives us the same sort of satisfaction and pleasure. (SW 2: 377/WWR 1:346)

Notably, Schopenhauer states that being pleased at the recollection (Erinnerung) of pain is 'the only way' to enjoy our present possessions. Furthermore, he adds that pleasure may be stimulated not only by relief from our own recollected pain, but also by witnessing the pain of others. Schopenhauer clarifies, by quoting Lucretius, that this pleasure comes about not because 'we like to see another person in pain, /But because it pleases us to know that we are free of this evil' (Lucretius, De rerum natura, II. 3-4). That is, it prompts reflection on the negative goods that we already possess, and thus indirectly stimulates pleasure. There is no reason to think that this kind of reflection is not possible without the external prompt of someone else's suffering. This is sometimes called counting one's blessings.

These two points suggest two qualifications to add to Schopenhauer's account of felt pleasures. First, a transition from pain to painlessness in the fulfilment of a desire is not sufficient for felt pleasure, for it must also be accompanied by some recollection of the previous painful state. This explains why, after all, pleasure is not automatically felt at the transition from pain to painlessness but rather is an opportunity that is often missed. Second, such a transition is also not necessary for felt pleasure, for the kind of pleasure that is stimulated by reflection on possible states of pain need not involve a previous painful state of one's own. It may be the case that felt pleasures often or usually involve a transition from pain to painlessness following the fulfilment of a desire, since the recentness of the pain may make it easier to recognise. This would explain why felt pleasures are typically of the kinetic kind. Still, Schopenhauer's account of how pleasure is indirectly stimulated is not exclusively kinetic, but fundamentally comparative. Fundamentally, for Schopenhauer, felt pleasure is only stimulated by the awareness that a pain that is possible for us is absent from our present state, whether it be a pain that we recall having had or one that, upon reflection, we recognise 
we could be having. It is the recognition of possible pain from the perspective of actual painlessness that enables us to feel the benefit of the (negative) goods we possess.

\subsection{The Value of Indirect Pleasure}

The development of the negativity thesis so far undermines the following possible reading of Schopenhauer's compensation argument: while the badness of things always presents itself as a painful feeling of some kind, the goodness of things always fails to present itself as a pleasant feeling or indeed any feeling; since no good ever registers as feeling, no good can ever compensate for the existence of evil. For it is simply not true that for Schopenhauer no good ever registers itself as feeling, even if it true that when it does, it does so indirectly.

Plus, regardless of how it presents itself as feeling, or fails to do so, it is not obvious why, for example, a small amount of suffering in the world could not be compensated by a significantly larger amount of its absence: a world mostly untroubled by suffering would seem preferable to its non-existence. Whatever role the negativity thesis does play in Schopenhauer's compensation argument, therefore, it cannot be merely that goods are metaphysically negative and pleasures psychologically indirect. More must be said about the implications of the negativity thesis for the value of pleasure.

An alternative way for the negativity thesis to support the compensation argument is suggested by Schopenhauer's language choices. The word translated as 'cancelled out', getilgt, means not only to erase but to repay. This is an example of Schopenhauer's general tendency to use financial metaphors to articulate his pessimism. For example, in the same passage the word for 'balance' is Bilanz, literally a balance sheet. Close by, there is:

human existence, far from having the character of a gift, has the completely opposite character of guilty indebtedness. The collection of this debt appears in the form of urgent requirements, tortured desires, and endless need, all introduced by human existence itself. Usually the whole span of life is spent paying off this debt: but this only pays off the interest. The capital is paid back in death. - And when was this debt contracted? - In procreation. (SW 3: 665-66/WWR 2: 595)

There is also the famous line: 'life is a business that does not cover its costs' (SW 3: 658/WWR 2: 589). Whatever this wisdom of Schopenhauer's use of financial metaphors Heidegger objects: 'Schopenhauer's well-known proposition ... is untrue not because "life" does cover its costs in the end but because life ... is not a business at all' (2002: 189-90) they illuminate a way for the compensation argument to work: the existence of evil can never be cancelled out by any good in the sense that an unrepayable debt is never cancelled out.

The negativity thesis explains why the existence of evil is like an unrepayable debt. As a rule, a (metaphorical) debt incurred by the commission of some bad cannot be paid off 
by the cessation of the same bad by which it was incurred. For example, the 'debt to society' incurred by someone who has committed a crime is not paid off by the mere fact that their crime ceased. If the crime is theft, then even the return of stolen goods is not compensation. The cessation of crime-doing may be better than its continuation, but, as this example demonstrates, being better is not sufficient for being compensatory. The debt to society can only be paid off with something positive in addition to the cessation of the crime, such as an proportionate fine or another appropriate punishment.

In the same way, if all good is merely the negation of some bad, as Schopenhauer claims, then whatever comparative value the existence of some negative good might have over the existence of any positive evil - and it may indeed have some - it is nevertheless not the right kind of value to pay off the (metaphorical) debt created by the existence of evil. Furthermore, since no positive goods would then exist at all, there would be no equivalent to the fine or punishment that might pay off a (metaphorical) debt to society. In Schopenhauer's world, goods may exist, but since they are all negative goods, no good exists that can compensate, in a metaphorically financial sense, for the mere existence of evil.

Elsewhere Schopenhauer makes a similar point, without using the language of debt, but still thinking very much along financial lines:

Whoever wishes to calculate the happiness of the course of his life according to [pleasures and delights] has seized upon the wrong criterion. For pleasures are and remain negative ... On the other hand, pain is felt positively; therefore, its absence is the criterion of happiness in life. And if a painless state is joined with the absence of boredom, earthly happiness has been essentially achieved; for everything else is a chimera. Now from this it follows that we should never purchase pleasures for the price of pain, indeed, not even for the risk of it, because otherwise we pay with something positive and real for something negative and hence chimerical. In contrast, we remain on the winning side when we sacrifice pleasures in order to avoid pain. (SW 5: 433/ PP 1: 356-7)

This argument, unlike the compensation argument, stops short of concluding that no life is worth living, but instead concludes that the happiest possible life is one without pain. (In his 'Aphorisms on the Wisdom of Life', from which this is taken, Schopenhauer's sole aim is to give advice for earthly happiness.) However, like the compensation argument, its conclusion is based on the claim that no pleasure can pay for any pain. Moreover, in this argument Schopenhauer is explicit that this claim follows from his negativity thesis. He is thus prepared to endorse the assumption attributed to him by the above development of the negativity thesis: namely that, due to its negativity, no good can repay for any evil.

Neither argument need assume that pleasures are rendered altogether worthless by their negativity. Although it is tempting to make this assumption - Schopenhauer says, after all, that they are 'negative and hence chimerical' - at the same time he considers pain's absence to be 'the criterion of happiness in life', which is a criterion of worth insofar he uses 
it to distinguish better possible lives from worse ones. While he does ultimately deny that any life is worth living, he does not deny that a life without pain is better than a life with pain; in fact, here he is asserting it. His point here, rather, is that a life without pain can get no better, and therefore that to trade such a life for any other, such as one with pain but also with compensatory pleasures, would be an error led by the delusion that such pleasures even exist.

Instead, it need only be assumed that - regardless of how they are felt or happen to be valued - negative goods cannot counterbalance the value deficit caused by the existence of any positive evil. Such a value deficit could only be counterbalanced by an independent positive good, which, according to Schopenhauer, does not exist. Positive good is the 'chimera' that we are purchasing, then, if we try to purchase pleasures for the price of any pain; and negative goods are 'chimerical' only when they are mistaken for positive ones.

\section{Philosophical Objections}

\subsection{Objection to the Experiential Thesis}

Simmons (2021) puts forward two sets of objections to the standard interpretation of Schopenhauer's compensation argument. One set are philosophical objections, and the other are textual objections. The first of Simmons's philosophical objections is to the 'experiential thesis' of Schopenhauer's negativity thesis. The experiential thesis is that 'we cannot directly experience any of life's goods' (Simmons 2021: 123). Simmons objects that the experiential thesis is false: 'we can directly experience certain pleasures' (Simmons 2021: 124). He gives three counterexamples: eating a delicious meal where every bite is savoured and not just reflected on afterward; being comforted by the recollection of a past accomplishment; and being excited by anticipation of a future event (Simmons 2021: 124). All these experiences, Simmons claims, seem to offer positive value to the person who has them, and should therefore be able to compensate for at least some of life's evils.

It is hard to deny that Schopenhauer does endorse a version of the experiential thesis, and Simmons's examples do put pressure on it. However, there are various ways that Schopenhauer might account for them.

\section{1.a. The Pleasure of Savouring Food}

When Schopenhauer applies his negativity thesis to the case of food, he conveniently focuses on the easy case of when it is consumed with little notice of the pleasure it might stimulate: 'a bite of food we have enjoyed ... stops existing for our feeling the moment it is swallowed' (SW 3: 659/WWR 2: 590). This leaves unexplained how the bite of food is enjoyed in the first place and, as Simmons stresses, even savoured. As a first line of response, Schopenhauer can point out that for cases of simply enjoying food, the transition from want to fulfilment is 
so recent that in many cases the comparison that ultimately stimulates all indirect pleasure is almost irresistible. While the taste sensation itself may be immediate, the pleasantness of the experience is not, for, Schopenhauer would insist, it still relies on recognition of the prior state of want. Otherwise, every enjoyable bite of food would be immediately enjoyed, but as we know from experience, sometimes not even the first bite is.

The case of savouring food, as distinct from repeated enjoyment of it, is made more difficult because it suggests a consistent level of felt intensity, which in turn would suggest that one is being held in a pleasurable state, rather than having transitioned to a state of fulfilment so recently that one can hardly resist comparing it with the state of want that preceded it. If there are such pleasures with an extendable duration and a consistent intensity, then these pleasures may be better thought of as positive and direct.

Here Schopenhauer has little recourse but to explain how indirect pleasures can, in fact, have an extendable duration and consistent intensity. This is not impossible for Schopenhauer, however, given the above development of the negativity thesis, for it includes the possibility of both intense pleasures, relative to the intensity of prior states of want, and extendable pleasures, due to the possibility of them being stimulated by reflection on such prior states, or possible versions of them. Thus, Schopenhauer would need to insist that pleasures with such features are only sustained by reflection on the state of want that is their prior condition. He might even suggest that such reflection is just what it is to savour a pleasure, when it is not simply repeated enjoyments of a pleasure.

\section{1.b. The Pleasure of Past Accomplishments}

Simmons's next two examples, unlike that of savouring a mouthful of food, do not seem to involve a recent transition from pain to painlessness or want to fulfilment. Marvelling at an accomplishment looks, on its face, to be a kind of static rather than kinetic pleasure: we would seem to be held in a state of awe or wonder at some accomplishment. When looking forward to an exciting event, we may anticipate a transition from pain to painlessness, but it has not happened yet. Nevertheless, according to the above development of the negativity thesis, a recent transition from pain to painlessness is not an essential feature of stimulating pleasure indirectly. The essential feature is the comparison between one's current state and a past or even merely possible state of privation. To account for Simmons's next two examples, therefore, Schopenhauer would have to postulate that some recognition of privation is involved in the pleasure of recalling a past accomplishment or anticipating a future event.

Along these lines, there are a couple of options for what could be going on in Simmons's example of recollecting an accomplishment. First, it might be that when recollecting an accomplishment in a way that stimulates pleasure, we are at the same time recollecting the state of privation prior to it. Recollection of this privation may make us happy in the present by allowing us to compare a (long) past privation with our current achievements. This may not be the case with all instances of pleasantly recollecting a past achievement but it would explain some, namely those where we recall having been relieved 
and, in doing so, relive that relief. Past accomplishments may continue to satisfy our current will, after all, but to derive any pleasure from this we do need some reminding.

Alternatively, the comfort of recalling a past accomplishment might consist in a comparison between our present circumstances and the counterfactual circumstances in which we never achieved them. We may feel comforted more by the fact that we are not, or were not, a loser than the fact that we are, or were once, a winner. In either case, in line with the above development of Schopenhauer's negativity thesis, the felt pleasure is ultimately stimulated in a comparative way, either by comparing one's current state of achievement with that actual state of want prior to the accomplishment, or by comparing it to the possible state of having never had the accomplishment.

Neither of these might seem to capture the experience of taking pleasure in a job well done, however, where we appear simply to marvel at our accomplishments, not focusing on what came before them, or how they might not have been, but only on the accomplishments themselves. Once again, this might better suggest the possession of something positive from which, if only we devote some attention to it, we can derive direct pleasure at any time.

But this already accepts an asymmetry between pleasure and pain that the negativity thesis better explains. For it does not explain why the pleasure of our accomplishments depend on our attention in the first place, why they do not provide us with direct pleasure all the time, whereas at least some area in which we are still lacking is always painfully and directly apparent to us. To try to explain this in terms of positive goods would explain neither why these goods, if they are supposed to afford positive pleasures, fail to command our attention when we do possess them, nor why their lack is immediately felt when we do not possess them.

Therefore, it may be too quick to conclude the apparent simplicity and directness of the pleasure taken in past accomplishments is best explained by taking that pleasure to be positive. For while this gives a simpler account of what we attend to in this pleasant recollection - namely the achievement itself, considered as a positive good - it does not account for why this pleasure depends upon recollection at all. An account for both, however, can be given in terms of the negativity thesis, although this does entail not taking at face value the apparent simplicity and directness of such recollection. Instead, when we are comforted by our achievements, really, we are taking comfort that they are or were not otherwise.

\section{1.c. The Pleasure of Anticipation and Hope}

Simmons's third example has a precedent in Georg Simmel, who objects to Schopenhauer as follows: 'The happiness of anticipation is not an illusion ... instead, quite legitimately and undeceivingly, the hope for happiness turns into the happiness of hope' (1991: 56). There is a sense in which Schopenhauer does claim that anticipation and hope are illusory: 'What is promised is not delivered, unless it is to show how undesirable the thing desired was: and so we are deceived now by the hope and now by what was hoped for' (SW 3: 657/WWR 2: 
588). That is, we are rarely made as happy as we think or hope we will be. This would be to miss Simmel's point, however, which is that hope itself really makes us happy while it lasts. Against this point Schopenhauer need not insist that the happiness of hope or anticipation is itself an illusion, but only that this happiness, too, is indirectly experienced. For this it helps to consider Schopenhauer's own views on anticipation and hope.

To start, Schopenhauer implies that it makes no difference to his negativity thesis whether a good is possessed now or anticipated in the future with a high degree of confidence:

we do not perceive as such the goods we possess or of which we are quite certain in advance [emphasis added]; this is because all pleasure is really only negative, and only has the effect of eliminating pain, whereas pain or misfortune is really what is positive and is immediately sensed. With possessions or the certain prospect of them [emphasis added] our demands immediately rise and increase our capacity for further possessions and wider prospects. (SW 6: 620-21/PP 2: 524-25)

The wider point Schopenhauer is making is a familiar one about the asymmetry between pleasant and painful feelings: such negative goods, whether they be in hand or in the future, do not immediately present themselves in the way that pains do. The new point is that the goods we strongly expect are just as (negatively) good as the goods we actually possess. Every advantage is taken for granted, even those yet to materialise. It would explain why 'what someone enjoys in advance by hoping for and expecting gratification, afterwards detracts from the actual enjoyment of it' (SW 6:315/PP 2: 267) - not simply because it is not as good as they expected, but because their expectation neutralised the enjoyment in advance.

Pleasure is possible only by not taking a given advantage for granted, although here Schopenhauer does not mention the qualification, developed above, that makes this possible: that pleasure may be derived from negative goods indirectly by reflection on previous or possible states of want. When this qualification is applied to cases of anticipation, it is unclear at first whether the relevant state of want would be a previous one, a possible one, or an actual one. For, on the one hand, the state of want that is logically and temporally prior to fulfilment is actual at the time of anticipation. Schopenhauer himself suggests that in the case of hope, desire coincides with confident knowledge of its future fulfilment: 'Hope is a state to which our whole being, namely will and intellect, concurs; the former in that it desires the object of hope, the latter in that it calculates it to be probable' (SW 6: 621n/PP 2: 525n). On the other hand, it remains true that at the time of anticipation, while the desired object is not yet possessed, the certainty of its future possession may still be counted as a negative good in the present, or - which is the same - it may be treated as such. Instead of the good of relieving actual, present want, however, it is the good of being protected from possible, future want; the former good still lies in the future at the point of anticipation, but the latter one is already possessed, or treated as being possessed, at that point. 
By taking both sides into account, Schopenhauer may have on his hands a good explanation for the indirect pleasure of anticipation. On the one hand, such pleasure is stimulated by reflection on the present, negative good of being protected from possible, future want. On the other, it might only fuel and inform such reflection that the future want from which one is protected remains actual in the present - like an itch one looks forward to scratching, or hunger on the way to the restaurant. It explains the heightened pleasure of any delayed gratification, which Schopenhauer might rather think of as anticipated relief.

So far, however, this only explains anticipation of future goods 'of which we are quite certain in advance'. Many cases of hope, by contrast, contain a degree of uncertainty. One might even say that anticipation without some element of uncertainty is not hope at all, but simply expectation. While it is easy to appreciate how expectations may be taken for granted even before they have been fulfilled along the lines Schopenhauer has suggested, it is harder to see how an object of hope can be taken for granted. It sounds like a contradiction in terms.

Here it is worth returning to Schopenhauer's claims about the delusory nature of hope. For Schopenhauer identifies two different ways in which we are deluded by hope. First, as already mentioned, there is the overestimation of how desirable an object of desire really is. Second, there is the overestimation of how likely we are to obtain the object of desire: 'Hope is confusing the wish for an event with its probability. But perhaps no one is free from the foolishness of the heart that so strongly distorts the intellect's correct assessment of probability that it regards one in a thousand as an easily possible case' (SW 6: 621/PP 2: 525). In these cases, the apparent element of uncertainty in cases of hope is (unconsciously) disbelieved by the hopeful. Indeed, it might be the very function of hope to allow us to treat an unreasonable expectation like a reasonable one. These cases can therefore be explained in the same way as cases of expected outcomes, that is, as simply taken for granted.

Although this explanation makes an appeal to the delusory nature of hope, it is not to deny, as Simmel insists, that happiness can be 'quite legitimately and undeceivingly' derived from hope. Though Schopenhauer would claim that it is only ever indirectly felt, and the point of the above has been to show how it could be, this does not provide any reason to doubt that one really feels happy as a result. Indirect pleasures are still pleasures, after all.

It does suggest a final difficult case of hope: hope that is undeceived even about its chances of fulfilment. For example, a lottery entrant who has realistic expectations about their low chances of winning. Here the explanatory power of Schopenhauer's negativity thesis may have reached its limit, for in these cases nothing is taken for granted, not even unconsciously. An option that may help, and would seem a possibility for the negativity thesis, is that desire can illuminate the negative good even of things that are not yet taken to be our negative goods. Happiness here would still be the indirect feeling of a negative good, only a potential, negative good and not a good that we possess. These might be taken for positive goods simply because we do not notice that their good would really consist in the elimination of the very desire by which they are illuminated. When someone derives happiness from the hope of winning the lottery, then, without being deluded, their happiness may be an appreciation of the (potential, negative) good that winning could do them. 
Although Schopenhauer does not discuss this option, it would be wise for him to assume it, for it explains how goods can even appear as such prior to their actual possession.

Taken as a whole, Simmons's three counterexamples do put pressure on the experiential thesis, that 'we cannot directly experience any of life's goods', entailed by Schopenhauer's negativity thesis. In each case, an elaborate application of the negativity thesis has been required on Schopenhauer's behalf. On the development of the negativity thesis so far, it has not been necessary to deny the experiential aspect to these pleasures altogether, but only to insist that they are nonetheless indirect experiences of life's goods. It has, however, been necessary not to take at face value apparently direct experiences of these goods. By taking pleasure in savouring the moment, reminiscing on the past, or anticipating the future, we are not simply deriving pleasure from a standing good, but are at the same time in some way recognising the absence of evil. There is an indication of this in that all of these pleasures are in some way effortfully maintained, that they require somehow directing attention towards the goods we possess, which is more consistent with Schopenhauer story that pleasures, being based on something negative, do not immediately present themselves whereas pains, being positive, do. This is harder to explain with a positive account of goods. ${ }^{3}$

\subsection{Objection to the Metaphysical Thesis}

Simmons's second philosophical objection to the standard interpretation addresses the 'metaphysical thesis' of Schopenhauer's negativity thesis (Simmons 2021: 124). The metaphysical thesis is that all pleasures are preceded by a painful desire. Simmons gives another series of counterexamples to support his objection that this thesis is false, including waking up from sleep to pleasant music, and discovering pleasure in things one never desired, such as food one never knew existed (Simmons 2021: 124).

There is very strong textual evidence to support Schopenhauer's endorsement of the metaphysical thesis: for example, 'a desire, i.e. lack, is the prior condition for every pleasure' (SW 2: 376/WWR 1: 345). Yet, there is also reason to think that Schopenhauer does not ultimately subscribe to the metaphysical thesis, for he presents at least two cases that are at odds with this thesis. One suggests the possibility of pleasure not preceded by a desire for the (negative) good on which the pleasure is based, while the other suggests the possibility of pleasure not preceded by any pain. In both cases he still maintains the negativity thesis.

In the first case, Schopenhauer is considering someone who is so surprised by a sudden stroke of good fortune that they are fatally overwhelmed by the shock. That a stroke of good fortune could have such an effect might suggest that it is caused by a positive good. Here is Schopenhauer's analysis of this case, which includes, and is indeed based upon, a reiteration of his negativity thesis:

That great strokes of good fortune can easily have a lethal effect when announced suddenly is based on our happiness and unhappiness being merely a proportional 
number between our demands and what we are granted ... this is because all pleasure is really only negative, and only has the effect of eliminating pain, whereas pain or misfortune is really what is positive and is immediately sensed. If ... the spirit is depressed by enduring misfortune and demands are kept to a minimum, then sudden strokes of good fortune do not find a capacity for their reception. That is, when they are not neutralized by pre-existing demands, they now have an apparently positive effect and so exert it with all their force, which can shatter the spirit and become fatal. (SW 6: 620-21/PP 2: 524-25)

We can take it that by an 'apparently positive' effect, Schopenhauer means more apparent than real: he is not backtracking on the negativity thesis. Instead, he has in mind a person so misfortunate that their desires have waned to a minimum: for example, to their most basic needs. When their fortunes are suddenly reversed and they attain goods that outstrip their minimal demands on life, their experience is a pleasurable one, indeed explosively pleasurable. They have therefore experienced a pleasurable transition from worse to better circumstances independently of any desire for their circumstances to improve in that direction. By Schopenhauer's own lights, then, certain pleasures can be experienced without being preceded by a (painful) desire because the removal of a lack of something can be a pleasurable experience without an antecedent desire for that lack to be removed.

The potentially lethal shock gives the appearance of a positive effect because, unlike the above-discussed case of an anticipated good, its effect has not been 'neutralized by preexisting demands'. The absence of a desire that would absorb the effect of the unexpected reversal of fortune, and prevent it from being such a shocking surprise, is what makes that effect apparently positive and potentially lethal. But at bottom, according to Schopenhauer, any pleasure, however potent, is still only negative, namely that of 'eliminating pain'.

This case strongly indicates that Schopenhauer accepts the possibility of intensely felt pleasures that are not preceded by desire, while at the same time consistently considering these pleasures to be indirectly experienced negative goods.

This case can still be said to involve pleasure preceded by a kind of pain, however; the misfortunate person is in some sense pleasurably relieved, after all. But antecedent pain, too, does not appear to be necessary for pleasure, according to Schopenhauer, given his other examples of how pleasure can be indirectly stimulated. As discussed further above, Schopenhauer acknowledges the possibility of stimulating indirect pleasure by reflection on states of privation and suffering that are merely possible for us. The example Schopenhauer gave is that of the pleasure prompted by witnessing the misfortune of others, which he fleshes out by reference to a passage in Lucretius in which we are invited to imagine standing safely above a stormy sea while the captain of a ship is in distress below (SW 2: 377/WWR 1: 346). We can assume that in this example we have never been in the position of the captain's specific pain, but merely by being made aware of its possibility for us, we indirectly feel the negative benefit of our current protection from it. Once again, this effect could be potent. This is a case, therefore, of someone who experiences pleasure indirectly even though this pleasure is not preceded by any pain for them. 
These two cases suggest that Schopenhauer does not, after all, subscribe to the metaphysical thesis that all pleasures are preceded by a painful desire. For in the case of an unanticipated reversal of fortune, pleasure is pointedly not preceded by a relevant desire, while in the case of reflection on merely possible misfortune, pleasure need not be preceded by any actual pain. For Schopenhauer, it need not be the case that pleasure is preceded by desire or pain, then, but only that advantageous circumstances are recognised as such by comparison to previous or merely possible disadvantageous alternatives. This can be seen when we bite into a delicious new food and exclaim, 'Where have you been all my life?!'

\subsection{Objection to the Experiential Requirement}

Simmons's third and final philosophical objection to the standard interpretation addresses the 'experiential requirement' of Schopenhauer's negativity thesis (Simmons 2021: 124). According to this requirement, 'something can have value for us only if we can directly experience it' (Simmons 2021: 123). Simmons uses more counterexamples to show that this requirement is false: for example, there is obvious value in having one's last will and testament carried out after one has died, even though one never experiences it.

The experiential requirement would seem to be an essential assumption in any standard interpretation of the compensation argument. Standard interpretations typically move from the negativity thesis to the conclusion that the goods in life are empty and without value. This move would be warranted by the assumption that something can have value for us only if we can directly experience it. Since negative goods can only ever be indirectly experienced, the argument would go, they cannot have value for us.

Schopenhauer may or may not in fact subscribe to the experiential requirement. However, on the non-standard variant of the standard interpretation, as developed above, his compensation argument does not (or need not) assume the experiential requirement. For, on the non-standard variant, the reason why negative goods cannot compensate for evil is not that, as things that are only ever indirectly experienced, they are generally valueless. Rather, the reason why negative goods cannot compensate for evil is that, as the mere negation of evils, whatever value they might be said to possess is not the kind of value that can pay off the debt caused by the existence of any positive evil. The discounting of negative goods for their compensatory value has nothing to do with how they are experienced, then, but simply to do with their negative nature, plus the logic of debt and repayment.

This is not to say that the mere negation of evil is not better than the existence of evil. It is better to be painless than in pain; indeed, as quoted above, Schopenhauer equates painlessness with earthly happiness. Negative goods are still goods in this comparative sense, and it seems Schopenhauer regards them as such. Nevertheless, the mere negation of evil cannot compensate for the existence of evil: someone who was being bullied is much better off when the bullying stops, but they are still far from being compensated. It follows that while we are right to value negative goods only as comparative goods, we are wrong to value them as compensations. It is in this more limited sense that they are without value. 


\section{Textual objections}

\subsection{Positive Aesthetic Pleasures}

Simmons's first textual objection to the standard interpretation of the compensation argument is that Schopenhauer appears to imply that aesthetic experience offers a source of positive pleasure and that these pleasures can compensate for suffering.

The first part of this objection takes its cue from Paul Guyer's (1996: 124-26) observation that Schopenhauer claims that there are two sources of aesthetic pleasure:

Cognition of the beautiful always posits the pure cognizing subject at the same time as, and inseparably from, the cognition of the Idea as object. And yet the source of aesthetic pleasure will sometimes be located more in the apprehension of the Ideas that are cognized, and sometimes more in the happiness and peace of mind of pure cognition that has been liberated from all willing and thus from all individuality and the pain that comes from it: and certainly this preponderance of one or the other component of aesthetic pleasure will depend on whether the intuitively apprehended Idea is a higher or lower level of the objecthood of the will. (SW 2: 250/ WWR 1: 237)

Guyer acknowledges that apart from one other mention (SW 2: 230/WWR 1: 219), Schopenhauer continues to treat the aesthetic pleasure as if it has only one source, namely the negative pleasure of liberation from willing. Nevertheless, it suggests that for Schopenhauer there is the pleasure of cognition as well as the pleasure of liberation. They are 'not necessarily phenomenologically distinct sorts of aesthetic pleasure', Guyer says, but they 'could be called positive and negative on account of their etiology' (1996: 126). A motive for retaining the two different pleasures in an interpretation of Schopenhauer's aesthetic theory is that the pleasure of cognition can distinguish the value of aesthetic experience from that of a drug-induced narcosis.

In other formulations of his aesthetic theory, Schopenhauer re-emphasises the strictly negative nature of aesthetic pleasure:

the will completely disappears from consciousness when an aesthetic perception appears ... This is the origin of that pleasure and that delight which accompany the perception of the beautiful. Thus it rests on the removal of the whole possibility of suffering. - If one were to object that then the possibility of delight would also be suspended, it should be remembered that, as I have often explained, happiness and 
satisfaction are of a negative nature, that is, they are merely the end of suffering, whereas pain is positive. (SW 6: 443/PP 2: 374-75)

He may have overlooked the fact that in previous formulations he has claimed that there is another sort of aesthetic pleasure, that of cognition, which seems to be positive in nature. If this is true, then Schopenhauer may be inconsistent.

On the other hand, Schopenhauer does not himself classify the aesthetic pleasure of cognition as positive in nature: that is Guyer's suggestion. Moreover, as Schopenhauer goes on, there is reason to think that he does not regard the aesthetic pleasure of cognition as conflicting with his stance on the general negativity of aesthetic pleasure.

For, after having first distinguished between the two separate sources of pleasure, Schopenhauer expands on what causes the aesthetic pleasure of cognition as follows: 'this is because [the Ideas] exhibit the greatest multitude of forms, as well as a wealth of profoundly significant appearances, and reveal the essence of the will to us most completely' (SW 2: 251/WWR 1: 238). Meanwhile, after reaffirming the negative nature of aesthetic pleasure, he expands as follows:

With the disappearing of all willing from consciousness, the state of delight still remains nonetheless, i.e., the absence of all pain and here even the absence of its possibility continue, in that the individual, transformed into a purely cognizing and no longer willing subject, remains conscious of itself and its activity precisely as such. As we know, the world as will is the first ... and the world as representation is the second ... world. The former is the world of longing and therefore of pain and thousand-fold woes. But the second is in itself essentially painless; moreover it contains a spectacle that is worth seeing, thoroughly significant, and at least entertaining. (SW 6: 443/PP 2: 375)

The final sentence suggests, albeit implicitly, a similar distinction between two sources of aesthetic pleasure. One source is the pleasure of painlessness after liberation from willing. The other, however, seems like an additional pleasure (i.e. 'moreover') taken in the 'thoroughly significant' (durchweg bedeutsam) spectacle (Schauspiel) of the world as representation in itself. Compare this to Schopenhauer's earlier description of the aesthetic pleasure of cognition as being taken in 'profoundly significant' (tiefe Bedeutsamkeit) appearances, and his claim that appearances that fail to produce this pleasure lack 'profound meaning' (tiefer Bedeutsamkeit). The similarity between the two points is not merely terminological: in both cases, Schopenhauer suggests that there is an aspect of aesthetic cognition which is worthwhile in a way that is connected to its being pleasurable yet distinct from mere painlessness. While in the earlier version he did not indicate whether this pleasure is positive or negative in nature, however, in the later one he gives a strong indication that it is not positive by having just reaffirmed the negative nature of all aesthetic pleasure. 
One could still push the point that Schopenhauer is being unknowingly inconsistent, for he has not yet indicated how aesthetic pleasure of cognition could be considered negative, and it would seem more natural to assume that it is a positive pleasure taken in the activity of our cognitive faculties. But note that according to Schopenhauer, aesthetic delight as 'the absence of all pain' consists in the 'purely cognising subject' remaining 'conscious of itself and its activity precisely as such' rather than as a 'willing subject'. Even consciousness of the activity of our cognitive faculties is, to him, a pleasure defined negatively. It seems, however, that this fundamentally negative pleasure is enjoyed in two different ways, depending on the depth and complexity of the object of aesthetic experience: for less cognitively engaging objects, we enjoy having no demands at all placed on us, either by the will or by cognition, while for more cognitively engaging ones, we enjoy having only cognitive demands.

The second part of Simmons's first textual objection is that Schopenhauer suggests that aesthetic pleasure can compensate for suffering:

The pleasure of all beautiful things, the consolation that art affords, the enthusiasm that allows the artist to forget the difficulties of life, this one advantage the genius possesses over other people and the only thing that compensates [entschädigt] him for his suffering (which is increased in proportion to his clarity of consciousness) and also for his desolate solitude among a race so different from him, - all this is due to the fact that, as we will continue to show, the in-itself of life, the will, existence itself, is a constant suffering, partly miserable, partly horrible; on the other hand, the same thing as representation alone, purely intuited, or repeated in art, free from pain, affords a meaningful spectacle. (SW 2: 315/WWR 1: 295)

On closer inspection, however, a few things become clear. First, the kind of compensation Schopenhauer mentions here is only relevant to the artistic genius. Second, the sufferings for which it compensates are only those that attach to being an artistic genius, namely the suffering that increases with one's intellectual powers and that of one's standing out from ordinary minds. The reference to compensation in this passage, then, is simply a way of expressing the fact that being an artistic genius has its upsides as well as its downsides, rather than one of them paying off the other like a debt, as it means in the compensation argument. Third, the passage continues by explaining that the upsides and downsides of being an artistic genius reflect the universally bad experience of the world as will, on the one hand, and the pleasure found in apprehension of the world as representation alone, on the other. Notably, in this passage, too, the source of aesthetic pleasure is the 'meaningful spectacle' (bedeutsames Schauspiel) such apprehension offers, as well as freedom from pain. However, as just argued, Schopenhauer indicates that this is not inconsistent with its being fundamentally negative.

\subsection{Pleasures that Fill Their Time}


Simmons's second textual objection addresses a parenthetical remark of Schopenhauer's that 'my present pain can never be annulled by future joys: these occupy [füllen] their time just as pain occupies its own' (SW 662/WWR 2: 592). According to Simmons (2021: 125) this could imply the existence of positive pleasures, insofar as these pleasures must be positive to 'fill up' (füllen) time and exclude other feelings. However, as Simmons also goes on to suggest, remarks about the ability of pleasure to occupy or fill up time may express not its positive nature, but simply the fact that pain and pleasure appear at different times.

\subsection{The Relevance of Temporal Arrangement}

The first two of Simmons's textual objections concern remarks from Schopenhauer that appear to imply the existence of positive pleasures that would contradict the negativity thesis. Simmons's third textual objection concerns the standard interpretation's proposal of a relationship between the negativity thesis and the compensation argument. As Simmons (2021: 125) points out, when Schopenhauer makes the compensation argument, he makes no reference to the negativity thesis. He does reaffirm it in the paragraph before the compensation argument, but not in the compensation argument itself. If anything, what is noticeable is the repeated emphasis that Schopenhauer places on the temporal arrangement of life's goods and evils. He claims, for example, that 'my present well-being does just as little to undo my earlier suffering', that evil is never cancelled out by good that exists 'alongside or after it', and that 'present pain can never be annulled by future joy: these occupy their time as pain occupies its own' (SW 3: 661-62/WWR 2, 591-92). This suggests an interpretation based on this temporal arrangement, which is the reading that Simmons prefers.

It is true that, textually, there is no smoking gun for the standard interpretation. On the other hand, Schopenhauer's emphasis on the temporal arrangement of life's good and evils is only a partial explanation for why goods can never compensate for evils. For it will not be immediately obvious to anyone that a good does not compensate for an evil simply because one comes after the other. Schopenhauer's temporal language is at best suggestive of a deeper reason. Simmons suggests that this deeper reason is a modified version of the experiential requirement: 'an evil can be compensated by some goods only if it is experientially related to those goods' (2021: 132). When goods and evils are separated in time, Simmons suggests, they 'experientially partitioned off' from one another (2021: 126) and thus unable to meet the modified experiential requirement.

However, first, while Simmons find the modified experiential requirement prima facie plausible, others will not. Second, it is unclear why two things separated in time cannot be experientially related to one another. Third, it would follow from Simmons's interpretation that goods can compensate for evils after all so long as they can occupy the same time, an objection which leads Simmons (2021: 129-30) to the dilemma of either admitting that this reading is faulty or charging Schopenhauer with overstating his case. Fourth, in the end, the modified experiential requirement would be an interpolation intended for interpretating the 
significance of Schopenhauer's references to the temporal arrangement of good and evils. There is little independent reason to accept that Schopenhauer does endorse it.

It would solve these problems if Schopenhauer's references to temporal arrangement could be explained in the terms set out by the non-standard variant of the standard interpretation, which assumes no version of the experiential requirement and relies on a thesis there is abundant evidence for believing that Schopenhauer's accepts, namely the negativity thesis. The question, however, is how this interpretation can explain those references.

To a limited extent, they can be explained away. For Schopenhauer's references to temporal arrangement in the compensation argument need not be thought of as very philosophically revealing at all, but rather a linguistic product of the logic of compensation. That is, Schopenhauer's language may simply reflect the fact that compensation cannot come before what is compensated for. At best, if some good is given in advance in exchange for having to undergo some bad, it is more like down payment of credit than repayment of a debt. This would explain why Schopenhauer never even raises the possibility that an evil can be compensated by a good that comes before it. Schopenhauer's references to the temporal arrangement of life's good and evil may therefore be no more revealing than when an aggrieved party says they can never be compensated, 'not now, not ever'.

However, there are alternative formulations of premises in the compensation argument in which the temporal arrangement of life's good and evils appears to have an ineliminable explanatory role:

[My present pain and my future pleasure] can no more balance one another than can the happiness of one individual balance the suffering of another; for in the end it is all the same whether the pleasure and pain, appearing at different times, take place in one and the same consciousness or in two. (HN 3: 651n/MR 3: 706n)

Here, like in the full formulation of the compensation argument, part of the reasoning seems based on an analogy between cases of intrapersonal compensation and cases of interpersonal compensation. The thought seems to be that the present pain can never be balanced by future pleasures within a life because the temporal separation of those pains and pleasures is no different from the separation between pleasures in one person's life and pains in another's. It would seem, then, that their 'appearing at different times' is not merely a function of the logic of compensation, but rather it actually explains why one can never compensate for the other.

This too, however, this is only a partial explanation, for it is indicated neither why the intrapersonal is analogous to the interpersonal, nor why one should accept that interpersonal compensation is not possible, and therefore that neither is intrapersonal compensation. If this is underpinned by the modified experiential requirement, as Simmons would suggest, then it faces the same difficulties listed above.

An alternative option is to reconsider what is being explained in the passage above. The previous reading naturally assumes that temporal separation (partially) explains why the 
pleasures within one life can never compensate for the pains. Alternatively, it can be read as explaining why pleasures and pains appearing separately within one life, rather than across separate lives, makes no difference to whether pleasure can compensate for any pain.

Someone could reasonably think that it would make a difference, after all. The explanation here would rely on the same claim that temporal separation within a life is no different from the separation between lives. It, too, would only be a partial explanation, for it would not explain why they are no different. However, importantly, it would not have the additional burden of explaining why pleasures can never compensate for pains, for that would not be the point being made, but rather a point assumed.

On this reading, when Schopenhauer's makes comparisons between interpersonal and intrapersonal compensation, his intention is to generalise the compensation argument across both cases, rather than to defend it by the analogy of one to the other. This leaves open what the compensation argument itself is based on. On the non-standard variant of the standard interpretation, as developed above, it can be based on Schopenhauer's own negativity thesis. ${ }^{4}$

\section{Acknowledgements}

I am deeply grateful for generous and constructive suggestions from Byron Simmons, who correctly pushed me to develop several points, which improved the work immeasurably. Any errors it still may contain are all my own. Since the germ of this work goes back to my PhD thesis, I am also grateful to my then supervisor Christopher Janaway. Finally, I thank the editorial team at the European Journal of Philosophy for their patience and promptness.

\section{References}

Works of Schopenhauer

Der handschriftliche Nachlaß [HN], 5 vols., ed. Arthur Hübscher. Frankfurt am Main: Kramer, 1970.

Sämtliche Werke [SW], 4th ed., 7 vols., ed. Arthur Hübscher. Mannheim: F. A. Brockhaus, 1988.

\section{Translations of Schopenhauer}

Manuscript Remains in Four Volumes [MR], trans. E. F. J. Payne, ed. Arthur Hübscher. Oxford: Berg, 1988-1990.

Prize Essay on the Basis of Morals [BM], in The Two Fundamental Problems of Ethics, trans. Christopher Janaway. Cambridge: Cambridge University Press, 2009.

Parerga and Paralipomena vol. 1 [PP 1], trans. Sabine Roehr and Christopher Janaway. Cambridge: Cambridge University Press, 2014.

Parerga and Paralipomena vol. 2 [PP 2], trans. Adrian Del Caro and Christopher Janaway. Cambridge: Cambridge University Press, 2015. 
The World as Will and Representation [WWR], 2 vols., trans. Judith Norman, Alistair Welchman, and Christopher Janaway. Cambridge: Cambridge University Press, 2010/2018.

\section{Other works}

Guyer, P. (1996). Pleasure and knowledge in Schopenhauer's aesthetics. In D. Jacquette (Ed.), Schopenhauer, philosophy, and the arts. Cambridge: Cambridge University Press.

Heidegger, M. (2002), Introduction to Metaphysics, trans. Gregort Fried and Richard Polt. New Haven: Yale University Press.

Simmel, G. (1991), Schopenhauer and Nietzsche, trans. Helmut Loiskandl, Deena Weinstein, and Michael Weinstein. Massachusetts: University of Massachusetts Press.

Simmons, B. (2021). A thousand pleasures are not worth a single pain: The compensation argument for Schopenhauer's pessimism. European Journal of Philosophy 29: 120-136

\footnotetext{
${ }^{1}$ Simmons (2021: $133 \mathrm{n} 2$ ) provides a full list of commentators on the compensation argument.

${ }^{2}$ I am grateful to Byron Simmons for alerting me to the distinction between kinetic and static pleasures, as well as its discussions in ancient Greek philosophy. The distinction as outlined above is attributed to Epicurus in Diogenes Laertius, Lives of the Eminent Philosophers, 10.136; the illustration in terms of thirst is found in Cicero, De Finibus, I.37-9. See also Lucretius, De Rerum Natura, II.627-9; and Plato, Republic, IX.538b-585a. In his presentation of the negativity thesis at SW 4: 210/BM: 202, Schopenhauer cites the passage from Plato. ${ }^{3}$ Schopenhauer is not out of the woods yet on this point. Additional, more difficult counterexamples along the same lines of thought could be produced, including potential cases of pleasurable anticipation that may not seem effortfully maintained: for example, the case of the child who, not knowing what to expect, would seem to be held in a state of excitement as she anticipates the presents that will arrive on Christmas morning. Perhaps, in line with the above defence of Schopenhauer, the child would cease to derive pleasure from anticipation as soon as she stops thinking about it. On the other hand, perhaps she spends the days leading up to Christmas in a constant buzz of excitement without any further effort or thought at all. I am grateful to Byron Simmons for raising cases such as these.
} 